\title{
Preparation of $\mathrm{BaTi}_{2} \mathrm{O}_{5}$ Single Crystal by a Floating Zone Method
}

\author{
Takaya Akashi, Hiroaki Iwata* and Takashi Goto \\ Institute for Materials Research, Tohoku University, Sendai 980-8577, Japan
}

Single crystalline $\mathrm{BaTi}_{2} \mathrm{O}_{5}$ was prepared by a floating zone method. The single crystal was transparent having a (001) cleavage plane. The space group was $C 2$, and the lattice parameters were $a=1.6909(9) \mathrm{nm}, b=0.3937(1) \mathrm{nm}, c=0.9419(4) \mathrm{nm}$ and $\beta=103.12(6)^{\circ}$. The permittivity perpendicular to a (010) plane showed the maximum value of 20500 at $748 \mathrm{~K}$. The permittivity perpendicular to (100) and (001) planes were about 140 and 70 , respectively, independent of temperature.

(Received January 28, 2003; Accepted February 24, 2003)

Keywords: $\mathrm{BaTi}_{2} \mathrm{O}_{5}$, single crystal, floating zone method, lattice parameter, permittivity

\section{Introduction}

$\mathrm{BaO}-\mathrm{TiO}_{2}$ system compounds, in particular $\mathrm{BaTiO}_{3},{ }^{1,2)}$ have been widely used for many dielectric applications due to excellent ferroelectricity and positive temperature coefficient (PTC). $\mathrm{TiO}_{2}$ rich $\mathrm{BaO}-\mathrm{TiO}_{2}$ system compounds such as $\mathrm{BaTi}_{4} \mathrm{O}_{9}{ }^{3,4)}$ and $\mathrm{Ba}_{2} \mathrm{Ti}_{9} \mathrm{O}_{20}{ }^{3,5,6)}$ are also expected as dielectric materials to be used at microwave frequencies. However, no report has been published on the compound having higher permittivity than those coumpounds in the $\mathrm{BaO}-\mathrm{TiO}_{2}$ system.

Many researchers have investigated on the $\mathrm{BaO}-\mathrm{TiO}_{2}$ phase diagram, ${ }^{4,7-11)}$ because the $\mathrm{BaO}-\mathrm{TiO}_{2}$ system includes several useful dielectric and ferroelectric materials. In those papers, the thermal stability of $\mathrm{BaTi}_{2} \mathrm{O}_{5}$ has been discussed. Figure 1 shows a part of phase diagram for the $\mathrm{BaO}-\mathrm{TiO}_{2}$ system by Rase et al. ${ }^{8)}$ They indicated the $\mathrm{BaTi}_{2} \mathrm{O}_{5}$ phase between $\mathrm{BaTiO}_{3}$ and $\mathrm{BaTi}_{3} \mathrm{O}_{7}$ in the phase diagram. However, Negas et al., ${ }^{9)}$ O'Bryan, Jr. et al. ${ }^{4)}$ and Ritter et al. ${ }^{10)}$ reported that the $\mathrm{BaTi}_{2} \mathrm{O}_{5}$ phase would decompose to

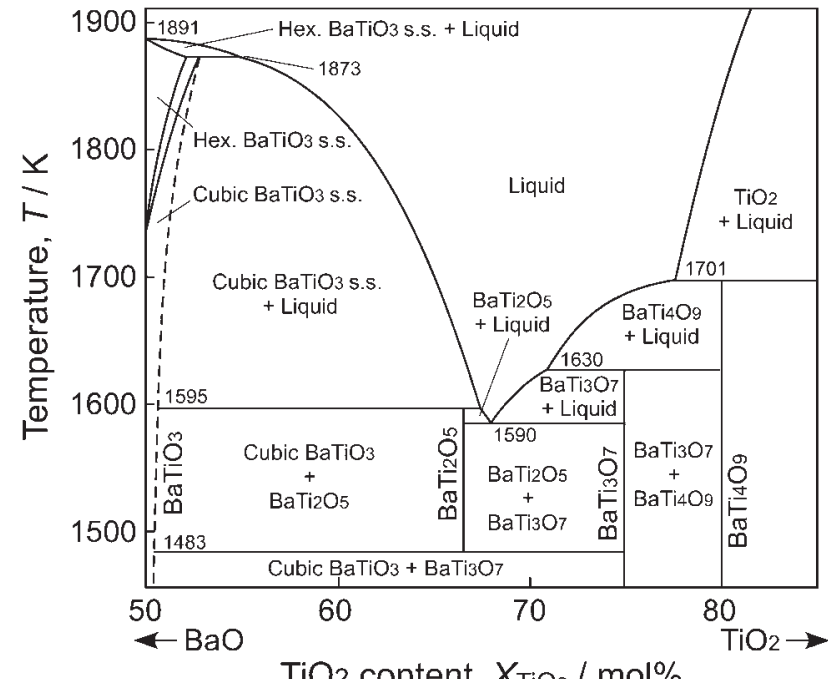

Fig. 1 A phase diagram of the $\mathrm{BaO}-\mathrm{TiO}_{2}$ system. ${ }^{9)}$

*Graduate Student, Tohoku University.

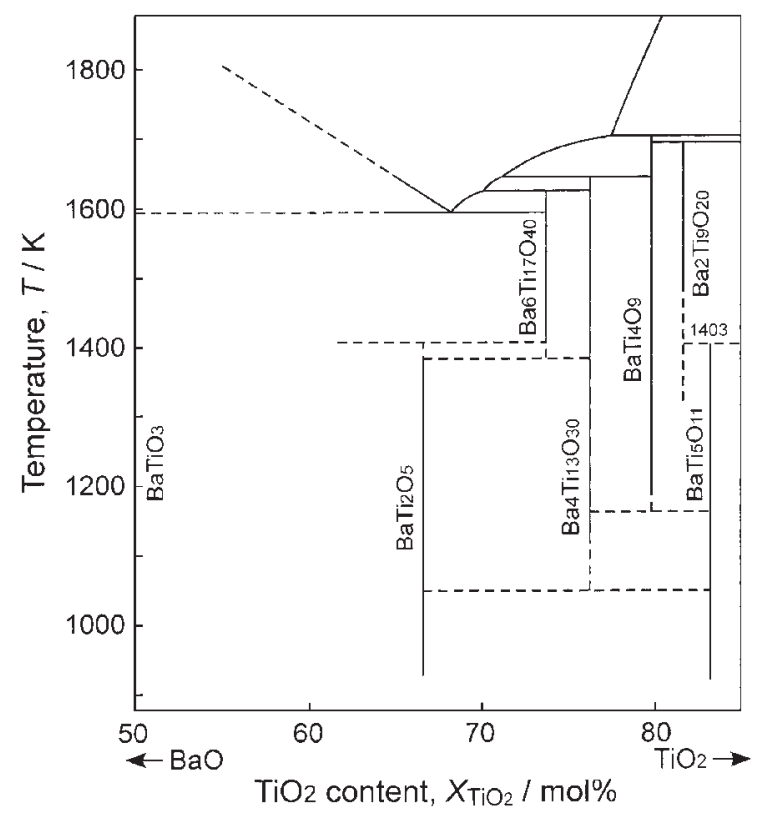

Fig. 2 A phase diagram of the $\mathrm{BaO}-\mathrm{TiO}_{2}$ system. $^{10)}$

$\mathrm{BaTiO}_{3}$ and $\mathrm{Ba}_{6} \mathrm{Ti}_{17} \mathrm{O}_{40}$ in the temperature range between 1423 and $1585 \mathrm{~K}$, and proposed a phase diagram as shown in Fig. 2. It has been believed that the $\mathrm{BaTi}_{2} \mathrm{O}_{5}$ phase could be stable under $1420 \mathrm{~K}$, and therefore no one has synthesized $\mathrm{BaTi}_{2} \mathrm{O}_{5}$ from a melt solidification process such as a floating zone (FZ) method.

The crystal structure and phase transformation of $\mathrm{BaTi}_{2} \mathrm{O}_{5}$ have been discussed by using polycrystalline specimens in literatures; ${ }^{4,8-12)}$ however, no electrical property of single crystalline $\mathrm{BaTi}_{2} \mathrm{O}_{5}$ has been reported. In this study, single crystalline $\mathrm{BaTi}_{2} \mathrm{O}_{5}$ specimens were first synthesized by a FZ method, and the relationship between crystal orientation and dielectric property was investigated.

\section{Experimental Procedures}

Dried powders of $\mathrm{BaCO}_{3}$ and $\mathrm{TiO}_{2}$ (99.9\% purity) were mixed with a small amount of ethanol in an agate motor in a molar ratio of $\mathrm{BaCO}_{3} / \mathrm{TiO}_{2}=1 / 2$. The mixed powders were isostatically pressed at $10 \mathrm{MPa}$ in a latex tube with $10 \mathrm{~mm}$ in diameter, and sintered at $1503 \mathrm{~K}$ for $43 \mathrm{ks}$ in air. The sintered 
rods were melted and directionally solidified by a FZ method at a rate of $5.6 \times 10^{-6} \mathrm{~ms}^{-1}$ in flowing $\mathrm{Ar}-21 \% \mathrm{O}_{2}$ gas. The phase was identified by powder $\mathrm{X}$-ray diffraction $(\mathrm{CuK \alpha})$. The crystal orientation was determined by pole figure X-ray diffraction.

The single crystalline specimens were cut perpendicular to (100), (010) and (001) planes. Permittivity was measured perpendicular to each plane using an AC impedance analyzer (Solartron 1260,1296 ) at frequencies from $10^{2}$ to $10^{7} \mathrm{~Hz}$ in air and temperature range between 293 and $1073 \mathrm{~K}$.

\section{Results and Discussion}

Figure 3 shows an as-grown directionally solidified $\mathrm{BaTi}_{2} \mathrm{O}_{5}$ specimen. The specimen was about $5 \mathrm{~mm}$ in diameter. Many cracks were observed and cleaved parallel to the growth direction. Transparent single crystals were cut from the as-grown specimens.

Figure 4 shows the $\mathrm{X}$-ray diffraction patterns of the powdered single crystalline $\mathrm{BaTi}_{2} \mathrm{O}_{5}$ specimen. Every peak was indexed using the space group of $C 2$ and lattice parameters of $a=1.6908(9) \mathrm{nm}, \quad b=0.3937(1) \mathrm{nm}, c=$

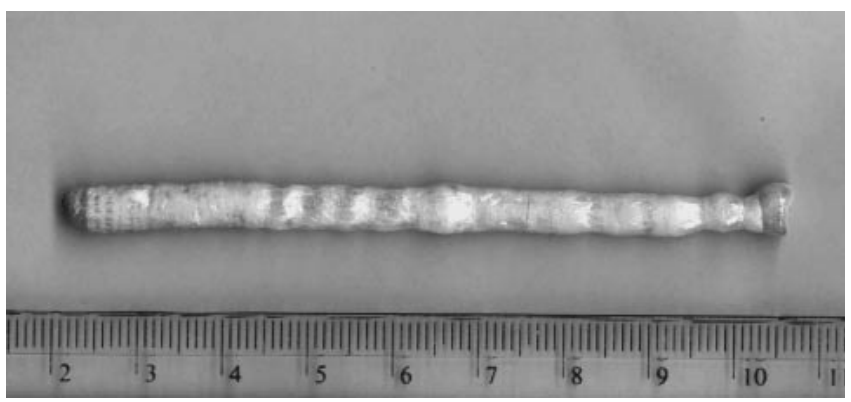

Fig. 3 As grown $\mathrm{BaTi}_{2} \mathrm{O}_{5}$ specimen by a $\mathrm{FZ}$ method.

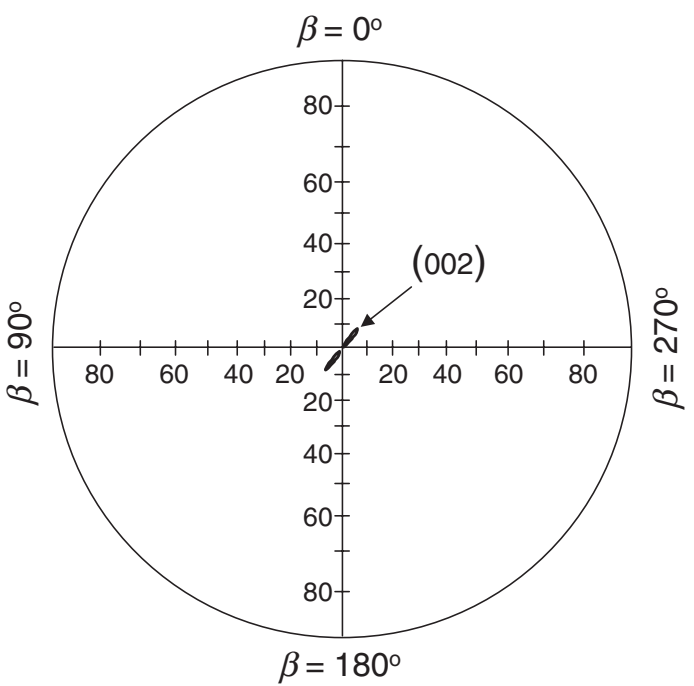

Fig. 5 X-ray pole figure from the cleavage plane of single crystalline $\mathrm{BaTi}_{2} \mathrm{O}_{5}$.

$0.9418(4) \mathrm{nm}$ and $\beta=103.12(5)^{\circ}$. No second phase was included in the specimen. These lattice parameters were in good agreement with the reported values of $a=1.6914 \mathrm{~nm}$, $b=0.3935 \mathrm{~nm}, c=0.9412 \mathrm{~nm}$ and $\beta=103.11^{\circ}{ }^{8)}$ The pole figure X-ray diffraction pattern from the cleavage plan is shown in Fig. 5. A (002) diffraction spot appeared at the center, suggesting that the cleavage plane could be parallel to the (001) plane. Figure 6 illustrates a schematic crystal structure of $\mathrm{BaTi}_{2} \mathrm{O}_{5}$. Distorted $\mathrm{TiO}_{6}$ octahedrons are connected at corners and/or edges, and layered parallel to the (001) plane. Ba atoms are located between the layers of $\mathrm{TiO}_{6}$ octahedrons. The cleavage nature of $\mathrm{BaTi}_{2} \mathrm{O}_{5}$ could be caused of the layered structure.

Figure 7 shows the permittivity of single crystalline $\mathrm{BaTi}_{2} \mathrm{O}_{5}$ perpendicular to a $(010)$ plane as a function of

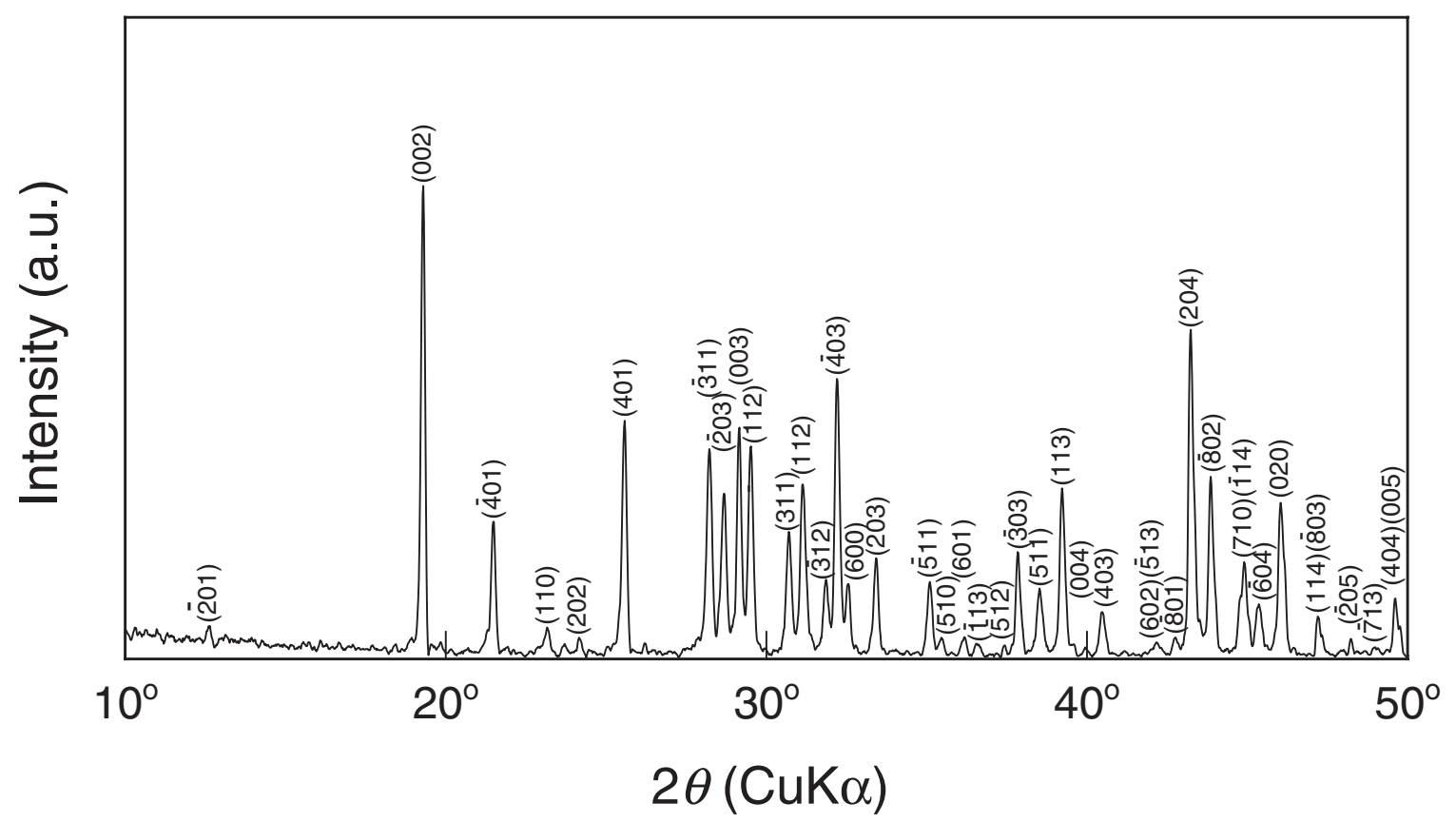

Fig. 4 X-ray diffraction pattern of powdered single crystalline $\mathrm{BaTi}_{2} \mathrm{O}_{5}$. 


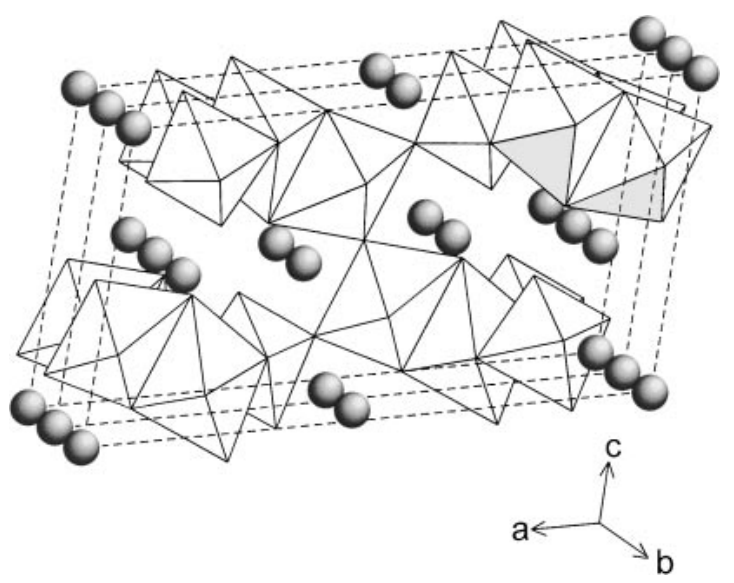

Fig. 6 A schematic crystal structure of $\mathrm{BaTi}_{2} \mathrm{O}_{5}$. Black sphere: Ba atom, octahedron: $\mathrm{TiO}_{6}$.

frequency. The permittivity of single crystalline $\mathrm{BaTi}_{2} \mathrm{O}_{5}$ perpendicular to the (010) plane decreased with increasing frequency, and almost constant around $1 \mathrm{MHz}$. The intrinsic permittivity values would be obtained at a frequency of $1 \mathrm{MHz}$.

Figure 8 shows the permittivities of single crystalline $\mathrm{BaTi}_{2} \mathrm{O}_{5}$ perpendicular to (100), (010) and (001) planes as a function of temperature at $1 \mathrm{MHz}$. The permittivity perpendicular to the (010) plane showed the sharp maximum of 20500 at $748 \mathrm{~K}$. This value was several times greater than those of $\mathrm{BaTiO}_{3}(\varepsilon=7600$ at $400 \mathrm{~K})$ and $\mathrm{Bi}_{4} \mathrm{Ti}_{3} \mathrm{O}_{12}(\varepsilon=600$ at $940 \mathrm{~K})$. The permittivities perpendicular to the $(100)$ and (001) planes were about 140 and 70 respectively, independent of temperature.

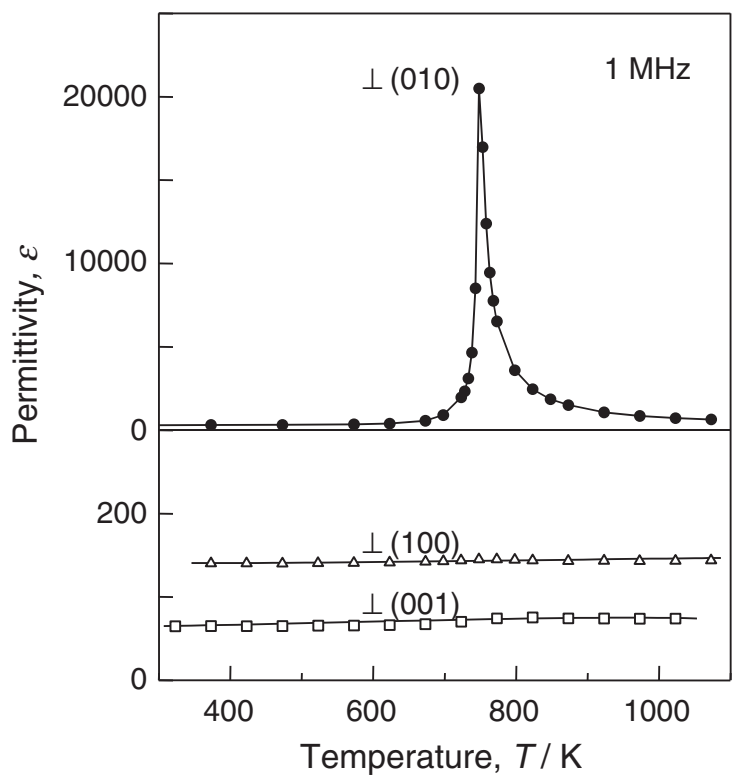

Fig. 8 Permittivity of single crystalline $\mathrm{BaTi}_{2} \mathrm{O}_{5}$ perpendicular to (100), (010) and (001) planes as a function of temperature $(f=1 \mathrm{MHz})$.

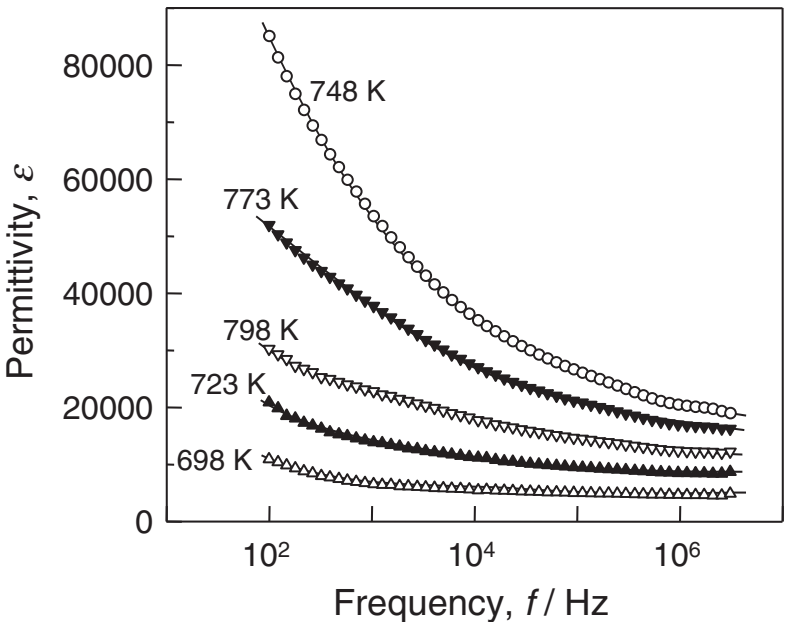

Fig. 7 Permittivity of single crystalline $\mathrm{BaTi}_{2} \mathrm{O}_{5}$ perpendicular to a (010) plane as a function of frequency.

\section{Conclusion}

Single crystalline $\mathrm{BaTi}_{2} \mathrm{O}_{5}$ was prepared by a $\mathrm{FZ}$ method. The specimens were transparent and cleaved parallel to the (001) plane. The lattice parameters were $a=1.6908(9) \mathrm{nm}$, $b=0.3937(1) \mathrm{nm}, c=0.9418(4) \mathrm{nm}$ and $\beta=103.12(5)^{\circ}$. The permittivity of single crystalline $\mathrm{BaTi}_{2} \mathrm{O}_{5}$ perpendicular to the $(010)$ plane showed the maximum of 20500 at $748 \mathrm{~K}$. This value is several times greater than that of single crystalline $\mathrm{BaTiO}_{3}$. The permittivities perpendicular to (100) and (001) planes were 140 and 70, respectively, independent of temperature.

\section{Acknowledgements}

The specimens were prepeared by using the facility at Laboratory for Advanced Materials, Institute for Materials Research, Tohoku University.

\section{REFERENCES}

1) W. J. Merz: Phys. Rev. 76 (1949) 1221-1225.

2) T. Akashi, K. Morita, T. Hirai, H. Yamane and T. Goto: Mater. Trans. 42 (2001) 1823-1826.

3) H. M. O'Bryan, Jr., J. Thomson, Jr. and J. K Plourde: J. Am. Ceram. Soc. 57 (1974) 450-453.

4) H. M. O’Bryan, Jr. and J. Thomson, Jr.: J. Am. Ceram. Soc. 57 (1974) 522-526.

5) H. M. O'Bryan and J. Thomson: J. Am. Ceram. Soc. 66 (1983) 66-68.

6) S. Nomura, K. Tomaya and K. Kaneta: Japan. J. Appl. Phys. 22 (1983) 1125-1128.

7) W. O. Statton: J. Chem. Phys. 19 (1951) 33-40.

8) D. E. Rase and R. Roy: J. Am. Ceram. Soc. 38 (1955) 102-113.

9) T. Negas, R. S. Roth, H. S. Parker and D. Minor: J. Solid State Chem. 9 (1974) 297-307.

10) J. J. Ritter, R. S. Roth and J. E. Blendell: J. Am. Ceram. Soc. 69 (1986) $155-162$.

11) K. W. Kirby and B. A. Wechsler: J. Am. Ceram. Soc. 74 (1991) 18411847.

12) F. W. Harrison: Acta Cryst. 9 (1956) 495-500. 